\title{
REVERSE INFORMATION MODELING FOR HISTORIC ARTEFACTS: TOWARDS THE DEFINITION OF A LEVEL OF ACCURACY FOR RUINED HERITAGE
}

\author{
C. Santagati ${ }^{1}$, M. Lo Turco ${ }^{2}$, R. Garozzo ${ }^{1}$ \\ ${ }^{1}$ Department of Civil Engineering and Architecture,University of Catania, Via Santa Sofia n.64, 95123, Catania, Italy - \\ cettina.santagati@dau.unict.it, raissa.garozzo@studium.unict.it \\ ${ }^{2}$ Department of Architecture and Design, Politecnico di Torino, viale Mattioli n.39 10125, Torino, Italy- \\ massimiliano.loturco@polito.it
}

Commission II, WG 8

KEY WORDS: Laser scanning, digital photogrammetry, 3D modeling, H-BIM, Level of Geometry, Level of Accuracy

\begin{abstract}
:
In recent years, there has been an increasing attention towards the use of the BIM (Building Information Modeling) approach in the cultural heritage domain. The stringent regulatory requirements in terms of BIM adoption in the field of public works in the short term will also have an impact on the historical heritage that characterises most European cities. However, when it comes to historical architecture, especially if it is in a state of ruin/abandonment, several critical issues arise. The first issue concerns the geometric simplification of architectural components provided by common commercial BIM platforms, that leads to search for other solutions. Another theme is the software interoperability, when sharing data between different platforms in order to enrich the digital model with not geometric information. Therefore, this research explores the concept of model tolerance and level of accuracy referring to a very complex architectural building. As case of study the church of Santa Maria delle Grazie in ancient Misterbianco (Sicily) has been chosen. The church was covered by the Etna eruption of 1669 and was recently brought to light during the excavations carried out by the Superintendence to Cultural Heritage of Catania. The state of decay of the church (warped floor, curved and out of lead walls, deteriorated altars and undamaged surfaces) makes it an excellent test bench on which to explore all the emerged criticalities, set up a feasible workflow and define a Level of Accuracy for complex or ruined architectural heritage.
\end{abstract}

\section{INTRODUCTION}

Heritage is our legacy from the past, what we live with today and we pass on to future generations (UNESCO). However, our heritage is subject to daily anthropogenic and natural risks and needs to be well preserved and maintained. One of the major weaknesses in the cultural heritage management process is due to the difficulty of handling heterogeneous information which are difficult to link together.

According to this, the adoption of a BIM approach in Architectural Heritage domain would allow for the development of semantically rich $3 \mathrm{D}$ models able to collect all the data in a unique relational database and to enhance communication between different stakeholders involved in the conservation, restoration and/or reconstruction process.

The best way to collect spatial and geometric data in Architectural Heritage field is the combined use of current 3D technologies (laser scanning and photogrammetry), which allow for high-resolution 3D models that discreetly record the skin of the building and give chromatic information on surfaces features and their state of conservation.

However, the reverse modeling process from the point cloud to a parametric geometric model compliant with common BIM platforms is still an open issue, plenty of criticalities and time consuming. It is a fact that a 3D model generated from point clouds can be considered a BIM product if its components have: parametric intelligence, relationships, and attributes (Arayci, 2008). On the other hand, we can argue that BIM platforms have been developed within the framework of Construction, Engineering and Facility Management (AEC/FM) industry. Dealing with historical architecture the first issue is related to the lacking of specific semantic libraries as well as to the high geometric simplification of architectural components provided by common use of commercial BIM platforms. Indeed, very often, particularly in presence of ruined, abandoned or very degraded architectures, the irregularities (lead out, deformations, recesses) are a part of the memory of the architecture and give useful information on its structural behaviour or collapsing dynamics.

Thus, it is fundamental to assess or to have benchmarks on the so called "modeling tolerance" as it is defined according UK BIM for Heritage requirements (Historic England, 2017) or on the "Level of Accuracy" as it is defined within the Finnish CoBIM requirements (2012) in terms of modelling the "asbuilt" situation. This will affect the LOD (Level of Development) of the components of the model, mainly in terms of LOG (Level of Geometry) and LOI (Level of Information), as they are defined in the italian legislation (Pavan et alii, 2017). The aim of this research is to investigate on data conversion (level of abstraction and generalization), LOG (graphic detail, as the control of purely graphical contents) and LoI (here intended as the dataset of information collected during the survey) in order to measure a sort of level of Accuracy, very required in the case of historical building "as-built" BIM (namely inventory BIM model).

The chosen case study is the church of Santa Maria delle Grazie in ancient Misterbianco (5 km far from Catania). It is one of the few evidences which survived the catastrophic events occurred at the end of the 17th century in eastern and south-eastern Sicily: i.e., the disruptive Mount Etna eruption (1669) that covered and erased 16 Etnean towns and the big earthquake (1693) that destroyed almost all the towns of the Val di Noto. The church was covered by the eruption of 1669 and was recently brought to light in the last years (2002-2009) thanks to the excavations carried out by the Superintendence to Cultural Heritage of Catania.

The state of decay of the church (warped floor, curved and out of lead walls, deteriorated altars and undamaged surfaces) makes it an excellent test bench on which to explore all the

\footnotetext{
* Corresponding author
} 
emerged criticalities, set up a feasible workflow and define a Level of Accuracy for complex or ruined architectural heritage. The paper is structured as follows: section 2 deals with literary review and methodology adopted in the research, section 3 will deepen case study description and data acquisition, section 4 will focus on the several workflows tested and the obtained results, section 5 will discuss the results, finally section 6 will conclude the paper.

\section{LITERATURE REVIEW AND METHODOLOGY}

Although the metric relief phase plays a main role in the interventions on Cultural Heritage, it is necessary to consider that the survey procedures, understood as an open system of knowledge, embrace a compendium of heterogeneous knowledge that can skillfully relate to each other through integrated approaches. That same integration that is typical of BIM oriented approaches. A current experimental area concerns the geometrical construction of architectural models starting from advanced and automated surveying techniques such as the laser scanner (Massari, 2017).

When dealing with BIM for historical architectural heritage, the first issue to consider is how to handle the uniqueness of each assets, how to generate geometrically and informative parametric architectural buildings components without losing the essence of the piece of art, its irregularities, its characteristic features. Indeed, the concept of Geometric parameterisation of an object have to be distinct in respect to informative parametrization.

That is, a BIM object could be not parametrizable from a geometrical point of view, but could embed all the notgeometrical information related to its history, state of conservation, restoration, etc. This could happen in presence of very ruined architectural heritage, where the idea of the modeling in a BIM platform would arise severe interrogatives on the level of abstraction required and in certain situations not suitable for the documentation of the object.

As indicated in BIM for Heritage. Developing a Historic Building Information Model (2017), modelling tolerance refers to how accurately a model fits against the as-existing survey (usually a point cloud). Requirements in terms of modelling tolerance should be defined at the beginning of the work and be part of the specifications of the project. Tolerances can vary across different areas of the asset or for specific building systems/ components, and can be expressed in $\pm \mathrm{mm}$.

Modelling tolerances specify the maximum possible divergence of the model from what is considered to be the primary source of asexisting geometric information, for example the point cloud.

Defining the modeling tolerance, brings to set the level of accuracy of a model related to the data from architectural survey, the references provided by regulations and international standards are very poor. An example of level of accuracy definition was set in 2012 from COBIM2012 - series 2. In this document, the authors establish the concept of an Inventory BIM model and the related Level of Accuracy is defined as follows:

"Accuracy levels of Inventory model - Requirement - The structures of old buildings are almost always somewhat slanted, sloping, curved or otherwise inexact in their geometry. Striving for "absolute" accuracy in the Inventory model is not appropriate [...]. The allowed measurement deviations for the Inventory model are: $10 \mathrm{~mm}$ on corner points of building elements, $25 \mathrm{~mm}$ on surfaces, e.g. walls and floors, $50 \mathrm{~mm}$ for old irregular structures such as roof structures".

The required LOD for BIM of an existing asset has direct implications in terms of metric data acquisition, mainly for the resolution specification (point density for laser scanning).

As known, in case of geometrically complex objects, typical of heritage projects, high levels of detail and modelling tolerances may be possible, but often counterproductive in terms of file size and performance, as well as the time-effort input required. A clear specification for the LODs is required in order to avoid over-modelling. The perceived benefits (in terms of information quality and completeness, visualisation requirements, etc) should be carefully weighed against model functionality, file restrictions and time-effort. In this direction, a novel approach for historical building modelling that takes into account the criticalities related to $3 \mathrm{D}$ surveying data conversion and the possibility have flexible LODs is given by Banfi (2016), who proposes the concept of ReversLODs. Regarding to the relationship between data and geometry, very different interpretation have been used by scientific and professional experiences; moreover, national laws, national and international standards have been introduced in the common practice. The acronym LOD is very used subject to different interpretations, intended as Level of Detail or Level of Development. A BIM object can be modelled at different levels of detail, depending on project requirements. The GRADE (GRAphic DEtail) refers only to the appearance of the object (geometry), not to the database that can be linked to the model (sometimes referred to as level of information; the term 'level of model definition' is used in PAS 1192- 2:2013 (BSI 2013b) to refer collectively to the level of detail and level of information in BIM (Chiabrando et alii, 2018). In this regard, the UNI 11337:2017 standard define the different LODs specific for restoration activities: "Restoration activities on existent construction considered of cultural interest imply a continuity of information management, and thus are based on data content and representation detail as resulting from the scientific conclusions made by the previous intervention (LOD F) implemented in successive management activities (LOD G)" (UNI 11337:2017).

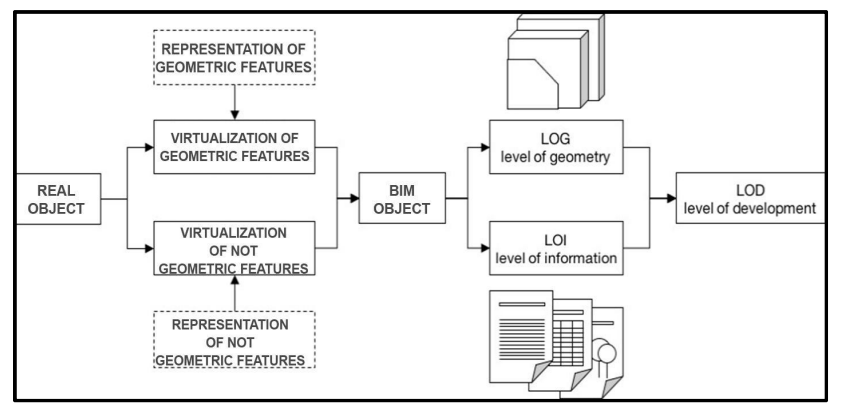

Figure 1. UNI 11337:2017. Standard on the "Digital management of IT processes in construction". Part 4: "Evolution and data development of models and objects"

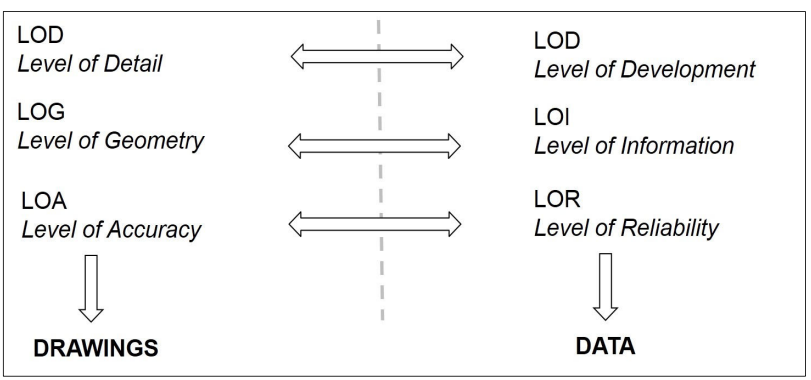

Figure 2. Different acronyms mentioned and defined in national and international standards

Directly linked to this, some important contributions produced by our scientific community define "rigorous" BIM approaches (Barazzetti, 2015) not only those that pursue exclusively a control of the Level of Accuracy in the comparison between 
manufactured and virtualized geometric model, but those procedures that contemplate:

(a) geometric flexibility to allow the same component to be replicated in other contexts by varying its dimensional values;

(b) a wealth of information that allows attributes of various kinds to be ascribed to the individual components modelled in the BIM environment.

In this research we focused our attention on architectural ruined heritage with the purpose of pushing to limits all the reasonings and known approaches on modeling tolerance and the definition of Level of Accuracy. The chosen case study is functional for the purpose of investigating and testing several workflows.

\section{THE ARCHITECTURE AND ITS SURVEY}

\subsection{Description of places}

As case study we chose the church of Santa Maria delle Grazie, mother church of the ancient Misterbianco $(5 \mathrm{~km}$ far from Catania, Italy), recently brought to light during excavation works carried out by the Superintendence of Cultural Heritage of Catania. The church was covered by the lava flow of the Mount Etna eruption which started the March $11^{\text {th }}, 1669$ and ended on $15^{\text {th }}$ July 1669 . The eruption quickly destroyed and submerged 16 etnean villages (including Belpasso, Nicolosi, Pedara, Mompilieri, Trecastagni, Camporotondo, Misterbianco, Mascalucia) and arrived up to Catania. n this lunar landscape, only few elements survived: a portion of the south wall and the bell tower of the church of Santa Maria delle Grazie in Misterbianco whose shape continued to stand out against the lava flow. After only 24 years, the severe earthquake of the $11^{\text {th }}$ January 1693 collapsed the belfry and part of the stem. Despite its state of ruin, the bell tower, named Campanarazzu, has marked the place where the destroyed village was settled.

During the time, professionals and amateurs get into the volcanic caves and discovered that several architectural elements of the church under the lava flow were still preserved (Politano et al, 1999). This lead the Superintendence of Cultural and Environmental Heritage of Catania to start a digging campaign carried out between 2001 and 2009 which interested the excavation of about 12 of basalt lava. At the end of the works, the entire layout of the church appeared partially preserved as well as walls, altars, flooring, plus a series of fragments of decorative elements (figure 3).

The site has an exceptional value: it represents one of the few architectural memories of the etnean area that survived both the Great eruption (1669) and the following earthquake (1693). It is an unique piece of architecture able to tell us a history of architecture, art and technology in the south-eastern Sicily of about four centuries (Santagati, 2017).

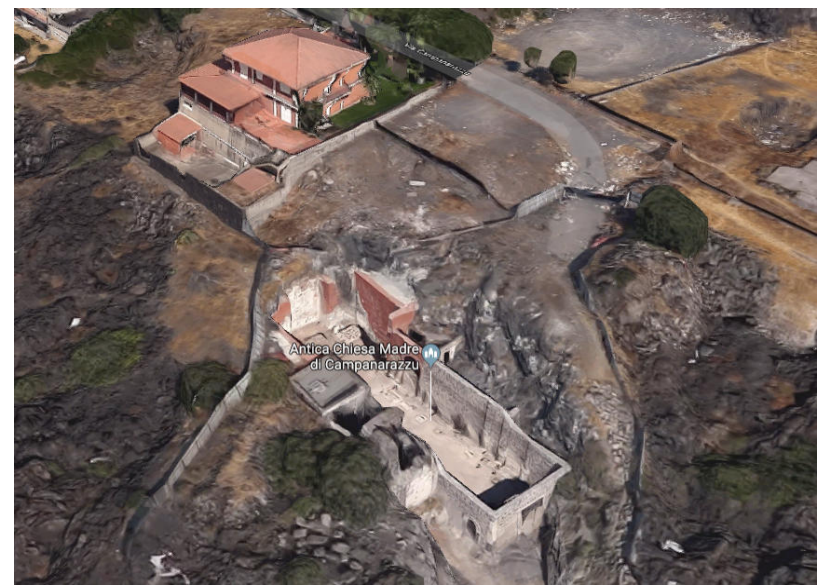

Figure 3. Church of Santa Maria delle Grazie after the digging campain and the first walls consolidation works. (Google Map) The church raised on a hill and was accessible via a 18 steps staircase. The longitudinal axis of the church is disposed on the East-West directrix along which lies the main entrance. The only surviving elements of the portal were the left abutment and pedestal (figure 4).

Regarding the other two entrances, one gives access to the nave, the other one to the presbytery. The portal of the first one, located in the southern wall, has been reassembled by the Superintendence. It represents an interesting example of Aragonese-Catalan architecture built between the $\mathrm{XV}^{\text {th }}$ and the XVIth centuries. The second one is only visible from the inside and is still "walled" with lava stones placed as protection by the inhabitants before leaving the site.

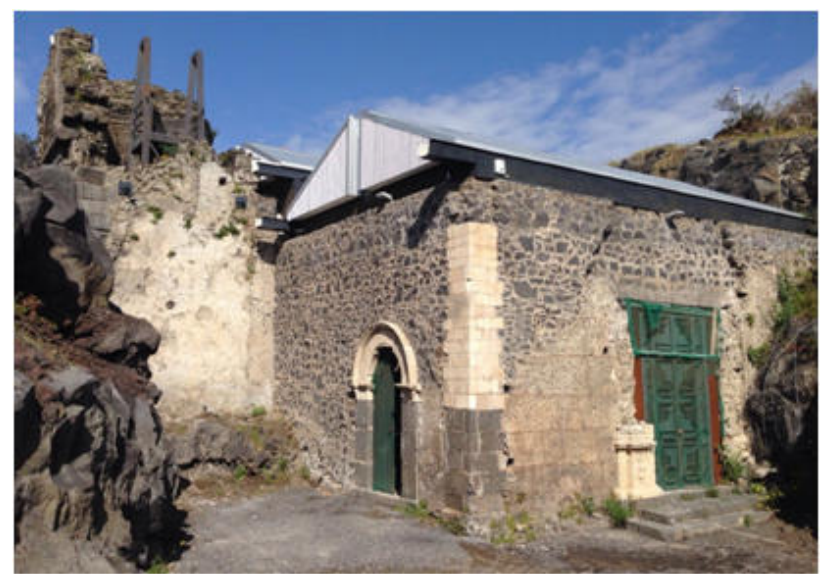

Figure 4. Main and lateral entrance to the church

The church, for the most part still narrow by the grip of lava, has a single nave $(40 \times 9 \mathrm{~m})$ concluded by a large presbytery closed by a rectangular apse. On the southern wall there is the access to the belfry tower and to the chapel of the Holy Cross. On the northern wall, hidden by the structure of the altar of the Madonna delle Grazie there is the so called Gothic chapel dedicated to Santa Maria delle Grazie, presumably the core the oldest church. It has a quadrangular plan covered by a cross ribbed vault.

The interior of the church was enriched by altars, built in XVII ${ }^{\text {th }}$ century. The floor, made in hexagonal terracotta tiles, is punctuated by the presence of hatches (some in lava stone, other in marble) that closed the access to the underlying burials (figure 5).

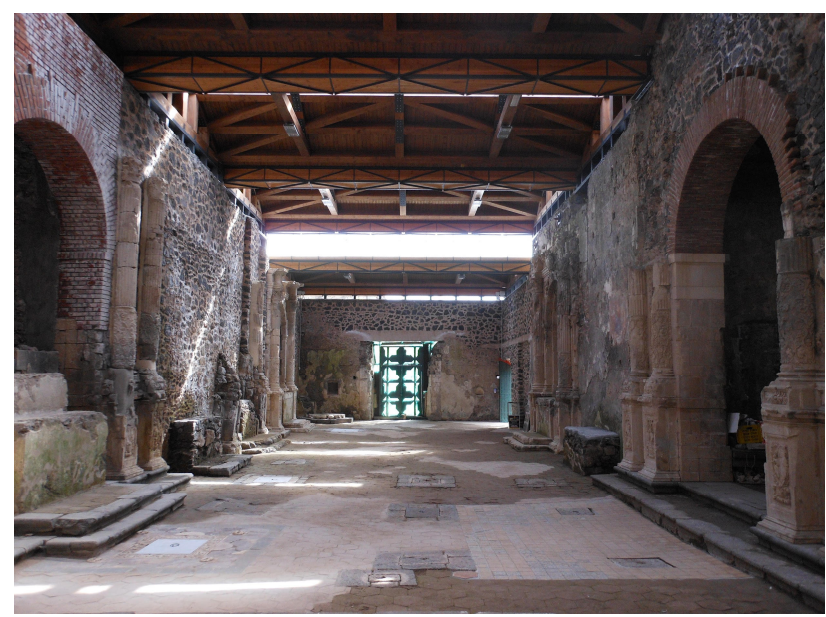

Figure 5. Interior of the church 
The bell tower has a quadrangular plan layout $(3.60 \times 3.80 \mathrm{~m})$ and is leaning against the southern side of the temple. It shares with the church the wall facing the South side of the nave, from which is it possible to access it. The surviving part of the belfry stands for 2 elevation. In the nearby lava flow it is possible to find the ruins due to the earthquake (walls, corbels, pieces of the steeple).

\subsection{D Data acquisition and processing}

The complexity of the site required the integrated use of current digital survey methods, terrestrial laser scanning (TLS) and digital photogrammetry (SfM techniques), for the acquisition of metric-dimensional data. Leica HDS 3000 laser scanner was used, supplied by the Laboratory of Architectural Photogrammetry and Surveying "Luigi Andreozzi" of the University of Catania. TLS survey foresaw 17 scans, 7 outdoor and 10 indoor, for a total of 107,422,501 points (figure 6).

In order to facilitate the subsequent registration procedures, six spherical targets were used for the alignment of external and internal scans. Once the data had been collected, the preprocessing, alignment and recording phases were carried out using Cyclone. The scans, treated with specific algorithms for noise reduction, were cleaned and then registered via targets or homologous points. The registration error is equal to $3 \mathrm{~mm}$.

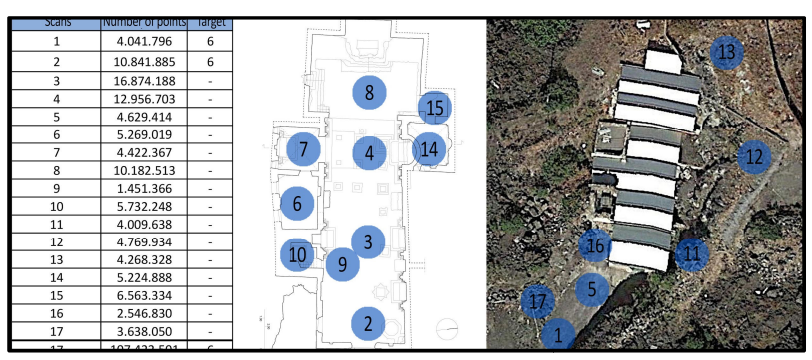

Figure 6. Surveying project

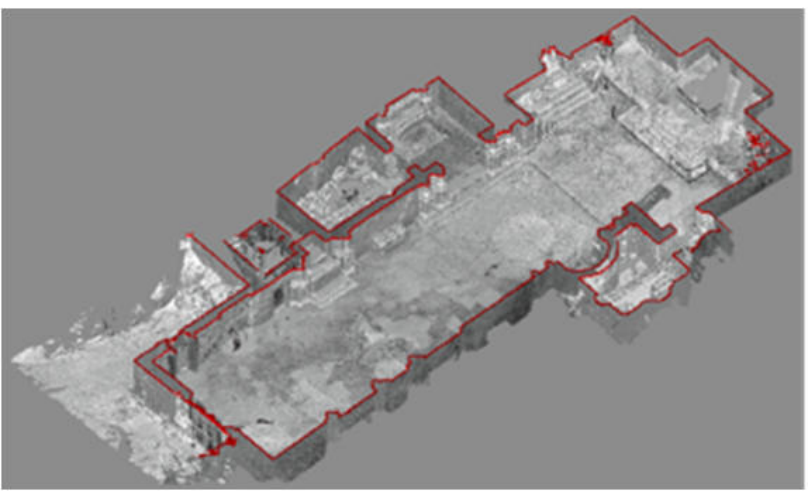

Figure 7. 3D view of the plan section of the point cloud (greyscale reflectance)

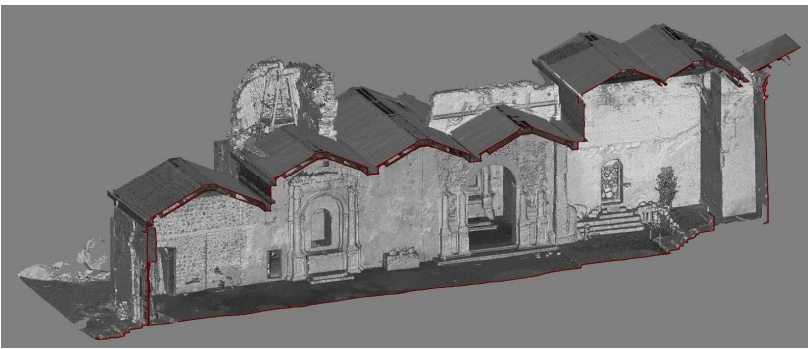

Figure 8 . 3D cross section view of the point cloud (greyscale reflectance)
At the same time and after data acquisition through TLS, numerous photographic datasets were produced, some of which were aimed at integrating the external scans by exploiting SFM techniques. The achieved 3D model is a digital copy of the studied object which provides information on the state of conservation of materials (TLS reflectance information).

The dense and accurate information given by the overall point cloud allows for a proper documentation both of the geometrical and the conservation status, as well as a more in-depth analysis of the signs that can be recognized on the architecture and useful to understand the reasons of the project, the transformations and changes (figs 7-8).

\section{FROM THE POINT CLOUD TO THE BIM MODEL}

The obtained point cloud discreetly describes the envelopes of the acquired surfaces. However, such information as far as detailed has no intelligence until it is semantically interpreted and geometrically parameterized. In any case, an historical architecture knowledge-based approach is fundamental for recognizing single architectural components: the understanding of the hierarchies and the links with the whole architectural building is crucial for achieving a proper classification and semantic decomposition of the architectural elements. In this case, the semantic decomposition interested the constructive components that constitute the building and the decorative elements that characterize the altars. For the scope of this research, three architectural elements have been chosen: the floor, the walls and the altars. They represent a significant sample for their degraded/ruined state of preservation. As BIM platform, Autodesk Revit, one of the most used in the worldwide has been chosen.

Regarding to the passage from the point cloud to the BIM model 3 different workflow have been set up and tested:

- Workflow 1: Point cloud $\rightarrow$ Mesh $\rightarrow$ BIM

Importing the point cloud (.pts) into Autodesk ReCap PRO and conversion into a mesh (.obj) via Autodesk cloud service; segmentation of the mesh in CloudCompare; conversion of the mesh from the .obj format to .dwg or .3dm format in Rhinoceros; importing the CAD format into Revit family editor for the creation of a semantic component.

- Workflow 2: Point cloud $\rightarrow$ Mesh $\rightarrow$ NURBS $\rightarrow$ BIM Importing the point cloud (.pts) into Autodesk ReCap PRO and conversion into a mesh (.obj) via Autodesk cloud service; segmentation of the mesh in CloudCompare; importing the mesh in Rhinoceros and conversion into a NURBS surface (patch) by means of Mesh2Surface plug-in; importing the NURBS (.dwg or .3dm) into Revit family editor for the creation of a semantic component.

- Workflow 3: Point cloud $\rightarrow$ BIM

Using Pointsense for Revit plugin (FARO) for the direct import of the point cloud in the family editor to model the semantic component.

\subsection{Floor}

The floor of the nave, visibly deformed because of the collapse due to the presence of the crypts below, has been the subject of numerous experiments aimed at obtaining an accurate object at an informative and geometric level. The extent of the deformation of about $0,21 \mathrm{~m}$ has made this component an interesting test bench, in the perspective to monitoring the deterioration and a general cognitive deepening during the time. 
4.1.1 Results Workflow 1: Importing mesh into the Revit project environment does not allow for automated creation of any building components or modification of the loaded element. For this reason, the method, although simple, fast, accurate and low cost (no plugins needed to be installed), was not considered suitable.

4.1.2 Results Workflow 2: The NURBS (patch), once loaded into the project as metric mass, was used for the automated creation of a roof that, in this way, acquired the implementability of BIM systems (figure 9). This approach is conceptually correct because the floor can be considered as an intermediate horizontal closure, covering the crypts and trampling the nave. The same procedure was attempted to create a floor, needlessly: this is probably due to Revit modeling constraints for floors elements. In conclusion, the proposed methodological procedure has the advantage of not requiring particularly long times, thanks to the almost total automation of procedures, and of returning an element geometrically accurate and semantically enrichable.

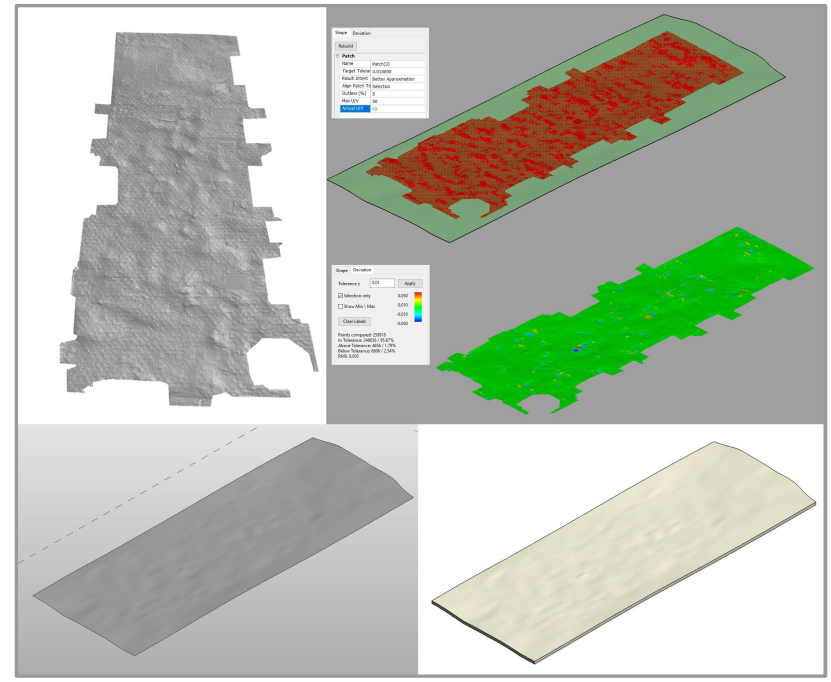

Figure 9. From the mesh to the NURBS and the creation of floor in BIM environment

4.1.3. Results Workflow 3: Once the point cloud was inserted into the project, the floor was modelled using as a reference level the height reached by the floor at the doorstep of the main entrance. Once created the range map and the polylines (oriented according to the short side of the compartment) the surface was deformed (figure 10). The floor thus obtained, consistent with the point cloud and parametric, is very heavy (in terms of surface control definition) and difficult to be managed, as it is not possible to deactivate the control points generated automatically during the procedure.

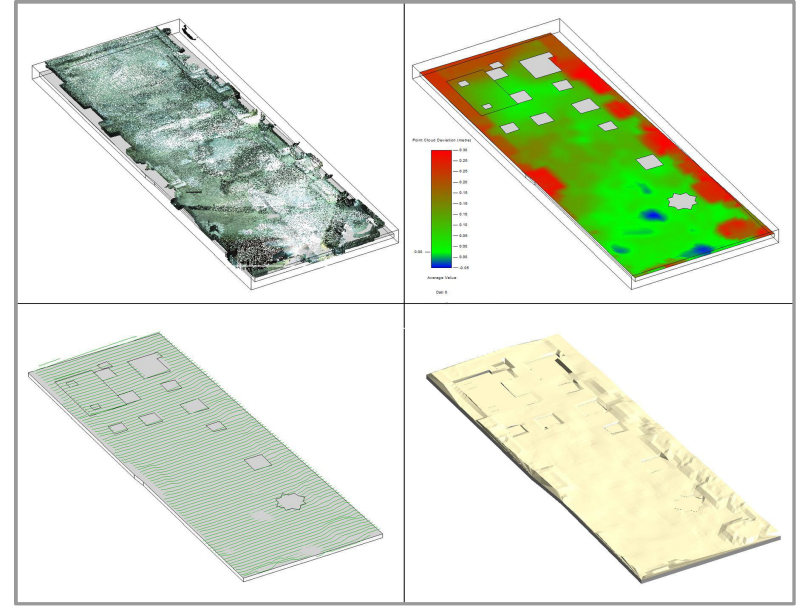

Figure 10. From the point cloud to the deformed floor in BIM environment

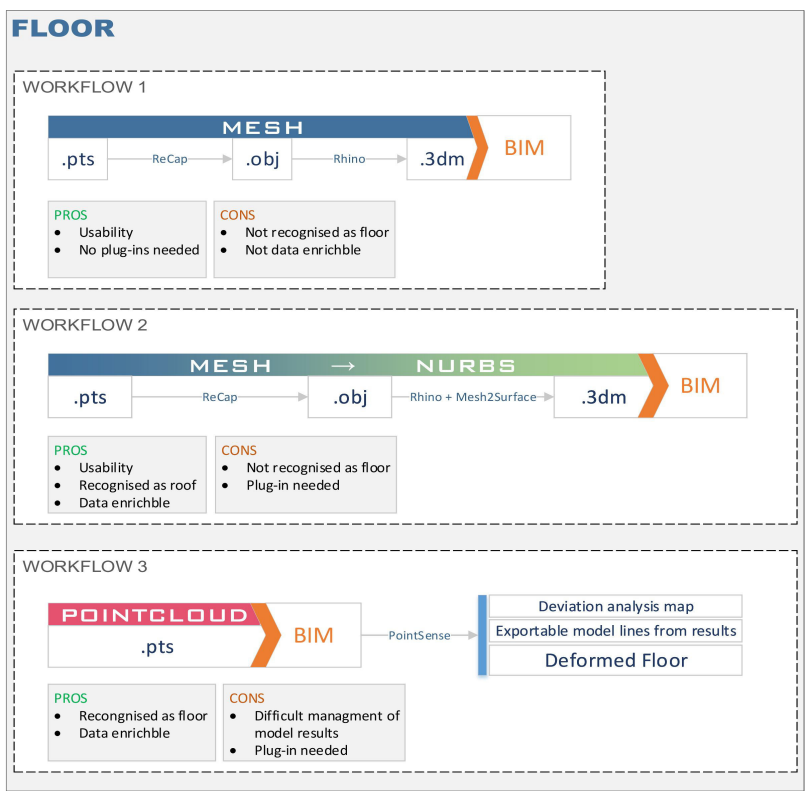

Figure 11. Synthetic schema that shows the results of the 3 workflows on the floor in terms of pros and cons

\subsection{Walls}

As said, the layout of the church emerged after a digging campaign, to realize a roof to cover the church, the Superintendence completed the existing walls. Thus, for the modeling of the walls in Revit we chose to create overlapping walls that were subsequently divided up, so as to guarantee consistent alignment and allow the irregular profiles of the connection of the respective masonry to be modified in a simple and not too time-consuming way. The state of ruin of the architectural work also makes the treatment of plaster deficiencies a matter of considerable interest: the deficiencies allow to investigate the construction techniques of that sixteenth-sixteenthcentury building almost completely disappeared in the Etnean area. Identified through appropriate sections of the point cloud two portions of masonry significantly affected by stripping and uneven (the maximum deviation from the axis of examined walls is 20 $\mathrm{cm}$ ), we sought a workflow that could transfer information on the deformation framework while maintaining the possibility of managing the stratigraphy of the wall element. 
4.2.1 Results Workflow 1: As in the previous case (4.1.1), importing the mesh into the Revit project does not allow the automated creation of any building component or modification of the loaded element.

4.2.2 Results Workflow 2: The NURBS (patch), inserted in the project as metric mass, was used for the automated creation of a wall in the project environment (figure12). Several problems were encountered: the creation of the wall from the imported surface is allowed only by setting certain thicknesses, less than $50 \mathrm{~cm}$ in both walls examined. Moreover, probably due to the complexity of the generated object, it is not possible to manage the stratigraphy: the model thus obtained is not fully implementable by heterogeneus data.

4.2.3 Results Workflow 3: Once loaded the point cloud into the project and modelled the wall in the Revit environment, taking as reference a horizontal section made at the ground connection, it was possible to generate only the range maps and deformation polylines exportable: deformation with PointSense is allowed only for walls and roofs. The analysis was therefore limited to the extrapolation of these data.

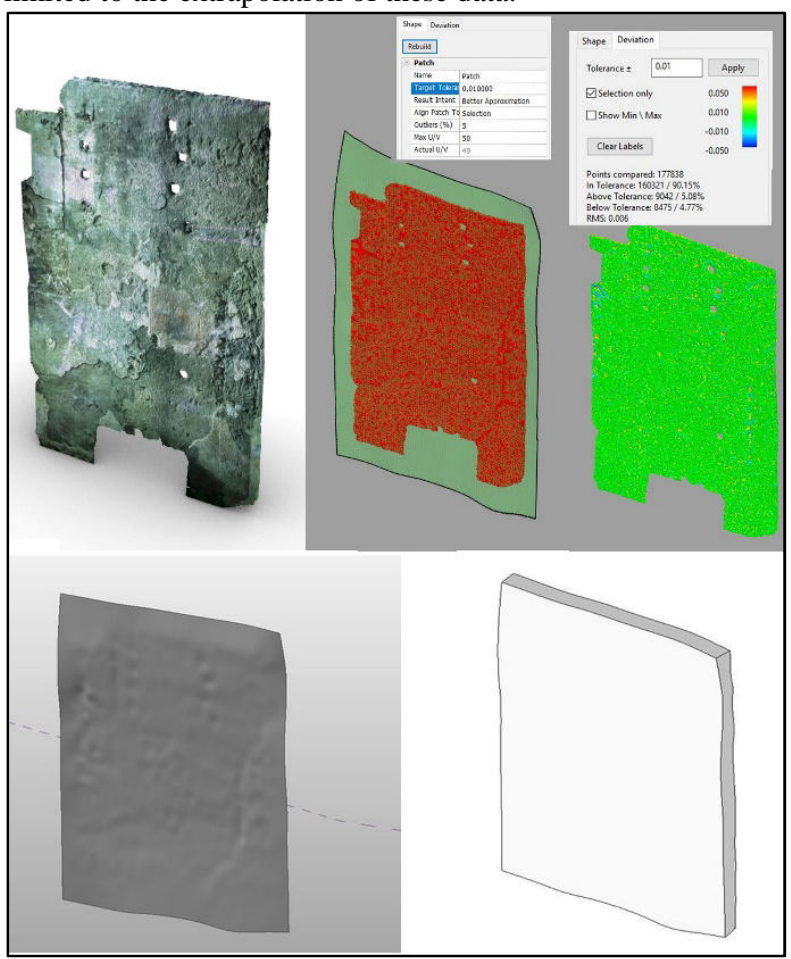

Figure 12. From the mesh to the NURBS and the creation of wall in BIM environment

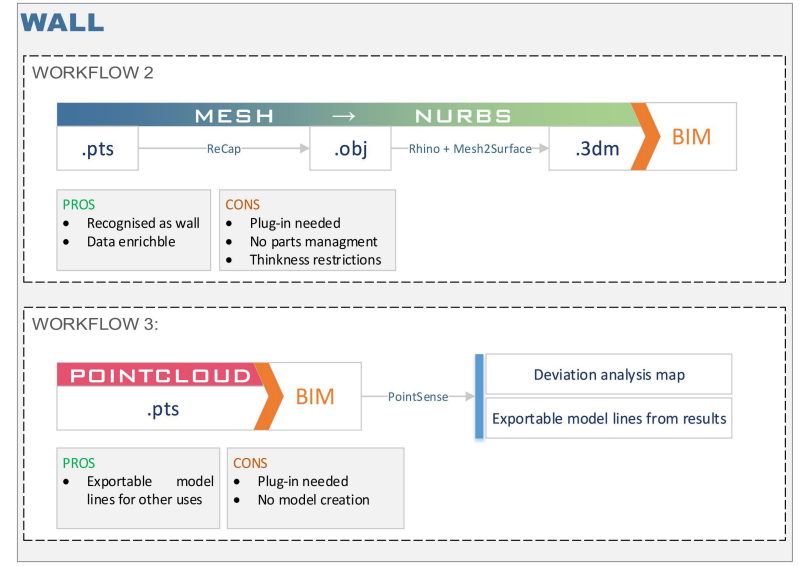

Figure 13. Synthetic diagram that shows the results of workflow 2 and 3 on the walls in terms of pros and cons

\subsection{Altars}

For altars and decorative elements, being these in a ruined state and having been subjected to reassembly of some detached portions after the excavation work, it was considered that the way of inserting the mesh in Revit (workflow 1) was the more appropriate solution than the modeling from scratch, without prejudice to the need for a possible enrichment of information of the individual models and the application of visibility filters that were effective even in the design environment.

4.3.1 Results Workflow 1: Once the mesh was generated and segmented into the single semantic elements identified, an operative sequence was sought to guarantee the loading of the single meshes in Revit and, at the same time, an easy alignment of the parts (figure 14). It was decided to use nested families, aligning them with the common reference system (preserved despite the many operations and conversions) during the loading of the parts into the host family. The possibility of applying visibility filters through the application of shared parameters was therefore verified; the colour variation prepared by the sample filter appeared effective only in the mesh edges (figure 15). The final result although functional, is not fully adequate from a graphic point of view.

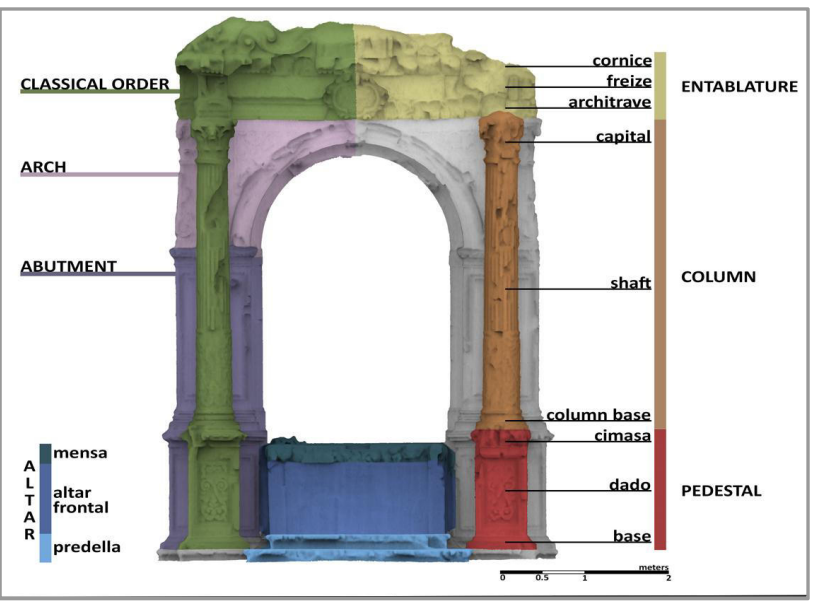

Figure 14. The semantic subdivision of the altar 


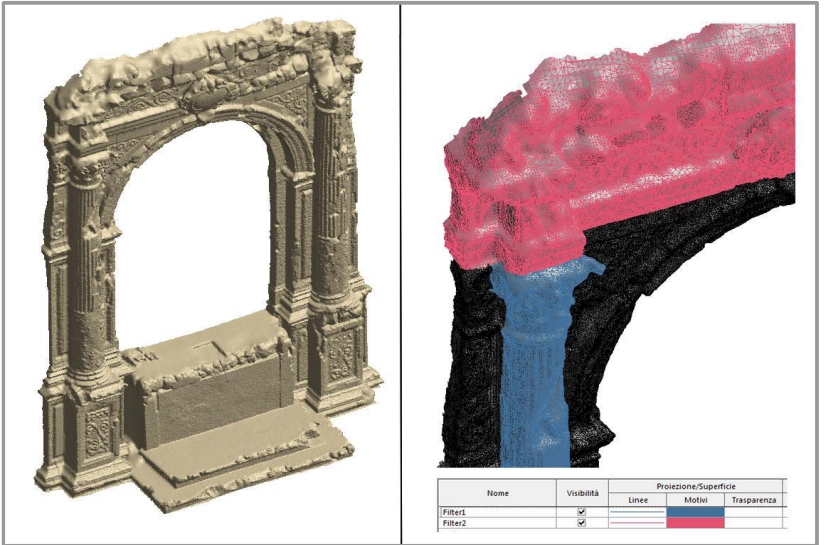

Figure 15 The creation of a nested family and the application of filters in BIM environment

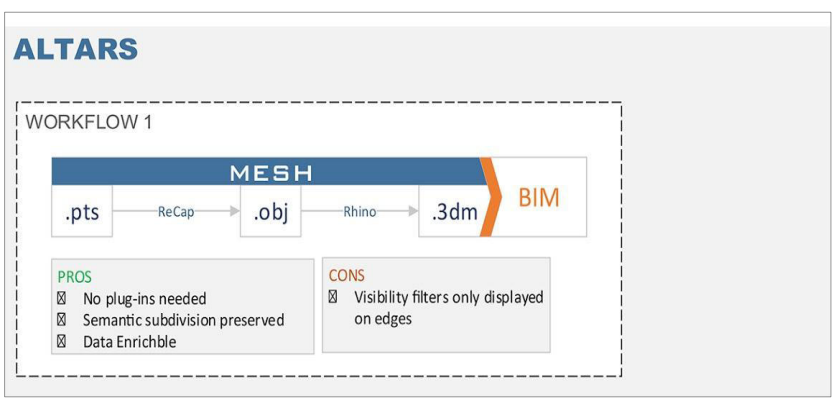

Figure 16. Diagram that shows the results of workflow 1 on the altars

\section{TOWARDS A LEVEL OF ACCURACY FOR COMPLEX AND RUINED HERITAGE}

The proposed approach allows the numerical measurement of the deviation between the measured artifact (converted into point cloud) and the virtual geometric model directly conducted within the BIM application in order to avoid one-way and noninteroperable processes. It must be said that the process requires the adoption of a specific plugin (such as Pointsense for Revit) exploiting the same BIM environment or the use of specific software such as CloudCompare.

In the proposed workflows, particular attention was paid to maintaining the semantic nature of the data. This allows to work in parallel on the alphanumeric attributes that allow the database to populate: archive documentation, project drawings, historical and current images, thematic decays surveys, instrumental detection techniques, dimensioned sketches, direct surveys, surveys of materials and stratigraphies are a compendium of information typical of an integrated approach. This resource allows us to imagine future lines of research in the direction of a measurement of the Level of Reliability of the survey (LoR).

Furthermore, it should be noted that the Scientific Community distinguishes the processes of acquisition of entire artefacts (global approaches) from those of individual architectural components (local approaches) (Biagini, 2016): in other words, in a global representation, the entire object is described, while in a local one only a portion of the object is characterized.

Although the case study refers to the entire building, given the heterogeneity of components, materials, geometries and epochs, it was preferred to describe the workflow of three examples (altar, walls and floors) that subtend different operating practices depending on the different building category to which these components are attributable in BIM environment. Therefore, the Level of Accuracy referred to the 3D restitution of objects will also relate to the actual dimensions of the component, with reference to different tolerances compared to the approach applicable to the entire building.

\section{CONCLUSIONS AND FUTURE WORKS}

This work tries to demonstrate that it is possible to develop and manage a HBIM model, starting from the checking of the metric accuracy: in particular, the conversion from numerical model (point cloud) to a mathematical and semantic 3D model is a process that involves simplifications and deductive hypothesis (Santagati, 2016).

Nevertheless, the high level of detail is an essential trait of information modelling of cultural heritage, in that the particularities (irregularities, uneven walls, depressions) eventually insignificant for the single technical activities may acquire a crucial relevance for other design choices.

To embed in the Cultural Heritage field such an articulated computerised management is an important goal for the next few years, despite the market is still unprepared to implement such a massive revolution. At the moment, the processes illustrated is time consuming and require significant and demanding data acquisition. It is thus crucial that the research environment shall actively cooperate with the software house for a systemization of automation processes based on ontologies and semantic recognition of information. On the other hand, BIM management may truly represent a means of systemizing and thus filing a series of both archiving and management data, which may be correlated and implemented as a critical support for the conservation process, from the restoration project/site "event" to the "duration" of the maintenance/conservation operation (Musso, 2013).

According to this, BIM procedures applied to the historic built environment first of all pose an initial difficulty arising from the need to model complex geometries. A second order of difficulty refers to the definition of a "Level of Reliability" for a numerical model (Bianchini, 2016) and, consequently, a corresponding level of simplicity that can be deemed acceptable in programming terms. On this issue, we would comment one topic more, related to different meaning of the word "measurability": the geometric issue is undoubtedly resolved and repeatedly mentioned in different documents that fully define the different metric detection operations. On the contrary, the ontological meaning intended as a quantitative enhancement of the reliability degree of a survey is not fully solved (Lo Turco, 2017).

These capabilities support interoperability scenarios, where the information, in various forms, can be made available to several professionals involved. Through interoperability traits, it is possible to figure out operating scenarios in which all actors can directly implement the recordings made in situ in an agile and accessible form. To do this, we need to support the object-oriented paradigm with conceptual aspects of their relational approach to the management of heterogeneous data, numerous and constantly updated. The most recent lines of research are opting for database integration and web-oriented tools, in order to be connected to the model (Quattrini, et al. 2017). Furthermore, the entire documentation produced in different stages of intervention is stored and make accessible. From a more scientific point of view, the application of these principles will allow to address and define a methodology for the knowledge (and the representation) of the Cultural Heritage, implying that the virtual reconstruction, the processing and communication of data become more transparent. Only a correct approach to knowledge, in fact, can reveal and enlighten the reasons underlying the construction and transformation of the building, as well as a correct interpretation of its geometric or technological features (Bianchini, 2016). It is therefore proposed a reflection on the integrated survey and design approaches, leading to a new form of Drawing, and expanding the 
frontiers of our discipline. The concept of cultural dimension is thus a greater formal qualification in a permanent relationship between architectural space and information space (Lo Turco, 2017).

\section{REFERENCES}

http://whc.unesco.org/ (last visit: March, 2018)

Arayci, Y., 2008. Towards building information modelling for existing structures. Structural Survey, Vol.2 6(3), pp. 210-222.

Banfi, F., (2016). Building Information Modelling - A Novel Parametric Modeling Approach Based on 3D Surveys of Historic Architecture. In: Ioannides M. et al. (eds) Digital Heritage. Progress in Cultural Heritage: Documentation, Preservation, and Protection. EuroMed 2016. Lecture Notes in Computer Science, vol 10058. Springer, Cham pp. 116-127

Barazzetti, L., Banfi, F., Brumana, R., Previtali, M. 2015, Creation of parametric BIM objects from point clouds using NURBS. In: The Photogrammetric Record, 30 (152), pp. 339-362.

Bianchini, C., 2016. Rip, Model and Learn (Thank you Brian!). In: Empler, T. (editor), 3D Modeling \& BIM. Applications and possible future developments, DEI Tipografia del Genio Civile, Roma, pp. 337-353.

Biagini, C., Capone, P., Donato, V., Facchini, N. 2016. Towards the BIM implementation for historical building restoration sites. In: Automation in Construction 71, pp. 74-86.

Chiabrando, F., Donato, V., Lo Turco, M., Santagati, C. (2018), Cultural Heritage documentation, analysis and management using Building Information Modeling: state-of-the-art and perspectives. In: Ottaviano E., Pelliccio A., Gattulli V. (Eds.), Mechatronics for Cultural Heritage and Civil Engineering, Springer, pp. 181-202

Chiabrando, F., Farina, S., Galleano, A., Lo Turco M., Naretto, M., 2017. Photogrammetry and HBIM for the knowledge and conservation of Villa Sarmatoris in Salmour, Piedmont. In: Empler, T. (editor), 3D Modeling \& BIM. Progettazione, design, proposte per la ricostruzione, DEI Tipografia del Genio Civile, Roma, pp. 230-245.

BuildingSmart Finland, 2012. COBIM - common BIM requirements 2012 Series 2 - modeling of the starting situation.

Historic England, 2017. BIM for Heritage. Developing a Historic Building Information Model.

Lo Turco, M., Mattone, M., Rinaudo, F. 2017. Metric survey and BIM Technologies to record decay conditions. In: The International Archives of the Photogrammetry, Remote Sensing and Spatial Information Sciences, Florence, Italy, Vol. XLII5/W1, pp. 261-268.

Massari, G.A., Cristofolini, A. 2017. Managing and integrating data for modelling the existent building heritage. In: Empler, T. (editor), $3 D$ Modeling \& BIM. Progettazione, design, proposte per la ricostruzione, DEI Tipografia del Genio Civile, Roma, pp. 246-259.

Musso, S. F. (editor) 2013, Tecniche di Restauro aggiornamento. UTET Scienze Tecniche, Torino.

Quattrini, R., Pierdicca, R., Morbidoni, C., Malinverni, E.S. (2017). Conservation-oriented hbim. The bim explorer web tool.
ISPRS - International Archives of the Photogrammetry, Remote Sensing and Spatial Information Sciences, Volume XLII-5/W1, 2017, pp.275-281.

Pavan, A., Mirarchi, C., Giani, M., 2017. BIM: Metodi e strumenti. Progettare, costruire e gestire nell'era digitale. Tecniche Nuove, Milano.

Politano, F., Santonocito, F., 1999. Ruins of ancient "Campanarazzu" buried by 1669 eruption. In: IXth International Symposium On Vulcanospeleology pp. 156-160

Santagati, C., Lo Turco, M., 2016. From structure from motion to historical building information modeling: populating a semantic-aware library of architectural elements. In: J. Electron. Imaging, 26(1), 011007.

Santagati, C. (2017). Heritage and Places: Rediscovering and Enhancing Cultural Identities Lost Under 1669 Mount Etna Lava Flow. In: Amoruso G. (eds) Putting Tradition into Practice: Heritage, Place and Design. INTBAU 2017. Lecture Notes in Civil Engineering, vol 3. Springer, Cham pp 392-401

UNI 11337:2017. Standard on the "Digital management of IT processes in construction". 